\title{
INOVAÇÃO CURRICULAR NA GRADUAÇÃO EM PERIÓDICOS DE EDUCAÇÃO FÍSICA A1 - B2 DO QUALIS/CAPES
}

\author{
Alfredo Cesar ANTUNES ${ }^{i}$
}

\begin{abstract}
RESUMO
O novo paradigma da sociedade da informação, o ciberespaço e suas consequentes transformações no mercado de trabalho provocam alterações em pontos-chave e eixos constitutivos da formação profissional, questionando a produção acadêmica sobre Inovação Curricular na graduação em Educação Física. Este estudo identificou e analisou fatores que caracterizam inovação curricular em periódicos científicos brasileiros, na área de Educação Física, entre os estratos A1 e B2 do Qualis Periódicos da CAPES (2013-2016), na versão on-line. Identificaram-se quatro fatores para a inovação curricular: o contexto em que o ensino ocorre, o status científico e político da área, os conteúdos a serem desenvolvidos e os procedimentos de ensino. Constatou-se que são necessárias outras pesquisas para identificar ações e propostas de inovação curricular e mais atenção ao tema da inovação curricular na graduação.
\end{abstract}

PALAVRAS-CHAVE: Inovação curricular; Ensino Superior; Educação Física; Currículo; Curso de graduação.

\section{CURRICULAR INNOVATION IN UNDERGRADUATE COURSES ON PHYSICAL EDUCATION JOURNALS A1 - B2 FROM QUALIS/CAPES/BRAZIL}

\begin{abstract}
The new paradigm of the information society, cyberspace and consequent transformations in the labor market lead to changes in key points and constitutive axes of professional training, questioning the academic production on Curricular Innovation in Physical Education undergraduate courses. This study identified and analyzed factors that characterize curricular innovation in Brazilian scientific journals, on Physical Education area, between strata A1 and B2 of CAPES Qualis Journals/Brazil (2013-2016), in the online version. Four factors were identified for curricular innovation: the context in which teaching takes place, the scientific and political status of the area, the content to be developed and the teaching procedures. Finally, it was found that further research is needed to identify actions and proposals for curricular innovation and its needed to pay more attention to curricular innovation in undergraduate courses.
\end{abstract}

KEYWORDS: Curricular innovation; Higher Education; Physical Education; Curriculum; Undergraduate courses.

\footnotetext{
${ }^{\text {i }}$ Doutorado em Ciência do Desporto/Educação Física pela Universidade Estadual de Campinas. Docente do Programa de Mestrado e Doutorado Interdisciplinar em Ciências Sociais Aplicadas da Universidade Estadual de Ponta Grossa. E-mail: alfredo.cesar@ hotmail.com - ORCID iD: https://orcid.org/0000-0001-9446-5316.
} 


\section{RESUMEN}

El nuevo paradigma de la sociedad de la información, el ciberespacio y sus consecuentes transformaciones en el mercado laboral conducen a cambios en los puntos clave y ejes constitutivos de la formación profesional, lo que lleva a preguntarse cómo es la producción académica sobre innovación curricular en la carrera de grado de educación física. Por lo tanto, el estudio identificó y analizó los factores que caracterizan la innovación curricular en revistas científicas brasileñas, en el área de Educación Física, entre los estratos A1 y B2 de CAPES Qualis Periódicos/Brasil (2013-2016), en la versión en línea. Se identificaron cuatro factores para la innovación curricular: el contexto en el que se lleva a cabo la enseñanza, el estado científico y político del área, los contenidos a desarrollar y los procedimientos de enseñanza. Se encontró que es necesario más investigación para identificar acciones y propuestas de innovación curricular además de una mayor atención al tema de la innovación curricular en el nivel de grado.

PALABRAS CLAVE: Innovación curricular, Educación Superior, Educación Física, Currículum; Carrera de grado.

\section{INTRODUÇÃO E PRESSUPOSTOS TEÓRICOS}

Compreender, por meio de análise documental, os elementos constitutivos que caracterizam indicadores de inovação curricular e relacionar com o processo de formação profissional em Educação Física no Brasil é o objetivo central deste estudo.

Ocorreram fatos significativos que influenciam no processo de formação de profissionais de Educação Física, tanto para o contexto escolar quanto para o não escolar (saúde, qualidade de vida, lazer e esporte de alto rendimento).

Destacam-se as mudanças nas diretrizes curriculares de formação profissional da área (BENITES; SOUZA NETO; HUNGER, 2008; ANTUNES, 2009, 2012). O próprio debate epistemológico da área é um fator fundamental para o processo de formação profissional (BRACHT, 2000; FARINATTI, 1992; SOUZA NETO, 2004; TOJAL, 2004; VERENGUER, 2003), e a regulamentação da profissão de Educação Física (Lei 9696/98) que também é um acontecimento marcante, apesar dos conflitos internos ${ }^{1}$, para o processo de formação profissional da área (BRASIL, 2002a; BRASIL, 2002 b; BRASIL, 2004).

Algumas mudanças no ensino básico brasileiro, como a reforma do ensino médio ${ }^{2}$ e a Base Nacional Curricular Comum $(\mathrm{BNCC})^{3}$, também proporcionaram debates e estudos sobre 
o processo de formação profissional em diversas áreas do conhecimento (MOTTA; FRIGOTTO, 2017), inclusive na Educação Física.

Além disso, a partir dos megaeventos esportivos (Copa do Mundo de Futebol 2014 e Jogos Olímpicos 2016) muito se discutiu sobre os legados para o esporte brasileiro, tanto no esporte de alto rendimento quanto no esporte educacional, no esporte de lazer e no esporte de inclusão social. Entre estes legados, está o aprimoramento do processo de formação dos profissionais que irão atuar nestas áreas (BRASIL, 2014; MARINHO; NASCIMENTO; OLIVEIRA, 2014).

Dessa forma, tais fatos são mostrados sem intenção de aprofundamento ou debate sobre suas particularidades, mas de alerta sobre as transformações que a área de Educação Física sofreu e sofre, fazendo surgir a dúvida sobre como o meio acadêmico está pensando a inovação na formação de seus profissionais diante desses fatos. O que se questiona, então, é: Como inovar o currículo diante dessas mudanças? E, mais desafiador ainda: Como prepará-lo para mudanças futuras? Ou melhor, como preparar os futuros profissionais para mudanças futuras? A produção de conhecimento científico na área fornece reflexões e instrumentos para essa preparação?

Entende-se que o olhar atento para a inovação curricular contribuirá para auxiliar no aprimoramento de ensino, aprendizagem e formação de profissionais da Educação Física. Ademais, é preciso pensar a inovação curricular na formação dos profissionais de Educação Física para o aprimoramento e acompanhamento das necessidades na nossa sociedade no que se refere à intervenção profissional, ou melhor, para a prestação de serviços à sociedade.

Assim, é fundamental, neste momento histórico, compreender e pensar o papel da inovação para o processo de formação profissional. A Inovação Curricular no ensino superior é consequência das transformações sociais e do papel das Instituições de Ensino Superior na sociedade. Conforme apresentado por Masetto (2004, p. 197), o conceito de inovação no ensino superior é “[...] o conjunto de alterações que afetam pontos-chave e eixos constitutivos da organização do ensino universitário provocadas por mudanças na sociedade ou por reflexões sobre concepções intrínsecas à missão da Educação Superior”.

$\mathrm{O}$ autor supracitado destaca como pontos-chave e eixos constitutivos para um projeto inovador no ensino superior, entre outros, o projeto pedagógico de um curso ou instituição, os 
objetivos educacionais, as disciplinas e atividades curriculares, conceito de avaliação, novas tecnologias, preparação dos professores e infraestrutura.

Em outro estudo, Masetto (2011) apresenta, com base em projetos curriculares no ensino superior, em diferentes instituições do mundo, pontos que diferenciam essas instituições de ensino como inovadoras. Destacam-se: os objetivos educacionais e perfis profissionais explícitos; gestão diferenciada com valorização da mudança; desenvolvimento de habilidades, atitudes e valores, além do intelectual; construção coletiva do currículo; atividades e disciplinas organizadas em função das aprendizagens necessárias ao profissional na sociedade; exploração de espaço e tempo além da instituição de ensino; metodologias que contemplem novas propostas de aprendizagem, além das tradicionais; e novas posturas do professor e dos alunos (neste ponto muitos aspectos são considerados para que ultrapasse a visão do professor como o detentor do conhecimento e o aluno como aquele que tenta absorver este sem participação ativa em todo o processo).

Somado a esses fatores, há um elemento-chave nesse processo de constante transformação e inovação - a internet que, com suas diversas possibilidades, leva a constantes transformações das nossas relações e como os profissionais de diversas áreas enxergam e convivem com o mercado de trabalho. Também cabe perguntar se os cursos de formação profissional estão atentos a essas possibilidades abertas pela internet.

A criação e o desenvolvimento da Internet nas três últimas décadas do século XX foram consequência de uma fusão singular de estratégia militar, grande cooperação científica, iniciativa tecnológica e inovação contracultural [...] a tecnologia digital permitiu o empacotamento de todos os tipos de mensagens, inclusive de som, imagens e dados, criou-se uma rede que era capaz de comunicar seus nós sem usar centros de controle. A universalidade da língua digital e a pura lógica das redes do sistema de comunicação geraram as condições tecnológicas para a comunicação global horizontal [...] A certa altura tornou-se difícil separar a pesquisa voltada para fins militares das comunicações científicas e das conversas pessoais (CASTELLS, 2012, p. 82$83)$.

O processo de formação profissional em Educação Física, no que concerne à inovação curricular, pode seguir três caminhos, no entendimento do autor. Primeiro, as Instituições de Ensino Superior (IES) estarem atentas para este movimento e agirem para transformar. Segundo, deixar que cada profissional/professor, por iniciativa própria, se aproxime dessa possibilidade, com o risco de alcançar ações isoladas sem influenciar a transformação do 
processo como um todo. Terceiro, continuar como está e correr o risco de tornar esse processo ultrapassado e, consequentemente, desnecessário.

Existem muitos motivos para advogar que os cursos de formação profissional em Educação Física devem estar em sintonia com o novo paradigma da sociedade da informação e não se abster da busca da inovação curricular ou não deixar a cargo somente das iniciativas particulares de seus profissionais, independentemente das suas habilidades e competências, pois trata-se de uma tarefa coletiva e não individual.

A Sociedade da Informação, o novo sistema multimídia de comunicação, que pode ser comparado em importância ao automóvel, borracha ou petróleo, forma essa nova galáxia da comunicação proporcionada pelos computadores (CASTELLS, 2012). Esse novo sistema fez surgir um novo paradigma social, cultural e econômico que trouxe mudanças na sociedade e, consequentemente, faz com que o processo de formação profissional também tenha que ser revisto e inovado. Assim, em sintonia com o conceito apresentado por Masetto (2004), esse novo paradigma impacta pontos-chave e eixos constitutivos do processo organizacional do ensino superior.

Como bem mostrou Castells (2012), o desenvolvimento da comunicação eletrônica e dos sistemas de informação tendem a alterar cada vez mais o cotidiano das pessoas no que diz respeito à saúde, ao trabalho, às compras, à educação básica e claro, às universidades.

O que está surgindo, porém, nas universidades de qualidade é a combinação do ensino on-line à distância com o ensino in loco. Isso significa que o futuro da educação superior não será on-line, mas em redes entre nós de informática, salas de aula e o local onde esteja cada aluno. A comunicação mediada por computadores está se difundindo em todo o mundo, embora apresente uma geografia extremamente irregular [...] (CASTELLS, 2012, p. 487).

O que se observa, na maior parte das vezes, nos cursos de formação profissional é uma prática pedagógica anacrônica. Atualmente, em boa parte das universidades, aula expositiva e sem diálogo com a sociedade em rede ainda é uma constante. Talvez, a busca por artigos em periódicos eletrônicos (on-line), o envio de trabalhos por e-mail ou aplicativos de mensagem seja o mais perto que se consiga chegar de uma rede. Mas, um alerta, esta comunicação em rede é muito irregular geograficamente, como diz Castells (2012). Principalmente no Brasil com suas dimensões continentais e desequilíbrios sociais. Assim, exemplos bem-sucedidos de 
inovação e uso das mais atuais tecnologias da informação coexistem com IES que estão muito distantes dessa experiência.

Vários fatores e características da Era da Informação devem ser levados em consideração no processo de formação profissional. O ciberespaço, por exemplo, transformou e continuará a mudar a forma de estar no mundo. Desse modo, os cursos de formação profissional também devem estar atentos para isso. De acordo com Lévy (1999) o ciberespaço é um

[...] espaço aberto pela interconexão mundial dos computadores e das memórias dos computadores [...] a perspectiva da digitalização geral das informações provavelmente tornará o ciberespaço o principal canal de comunicação e suporte de memória da humanidade a partir do início do próximo século (LÉVY, 1999, p. 92-93).

E Lévy estava certo, pois, hoje, pensar em comunicação e informações sem este conceito de ciberespaço é praticamente impossível. Da mesma forma, pensar em um processo de formação profissional sem acompanhá-lo também é algo insensato.

Lévy (1999) apresenta algumas constatações fundamentais para pensar no processo de formação profissional. O conhecimento adquirido no início da carreira se tornará obsoleto até seu fim, o trabalho dependerá da transmissão e produção de conhecimentos e saberes, o ciberespaço suporta tecnologias intelectuais que modificam funções cognitivas (memória, imaginação, percepção, raciocínios) favorecendo "novas formas de acesso à informação" e "novos estilos de raciocínio e de conhecimento". Ainda, afirma que

[...] duas grandes reformas são necessárias nos sistemas de educação e formação [...] a aclimatação dos dispositivos e do espírito do EAD ao cotidiano e ao dia a dia da educação [...] A segunda reforma diz respeito ao reconhecimento das experiências adquiridas [...] Organizando a comunidade entre empregadores, indivíduos e recursos de aprendizagem de todos os tipos, as universidades do futuro contribuiriam assim para a animação de uma nova economia do conhecimento (LÉVY, 1999, p. 158).

Dessa forma, busca-se um olhar mais próximo para o processo de formação profissional em Educação Física, a partir deste novo paradigma da informação. É preciso ultrapassar a informação puramente técnica ou teórica fechada em uma redoma. É necessário compreender a formação profissional em uma perspectiva mais abrangente, ou seja, neste novo paradigma 
social da informação, a partir de elementos econômicos, culturais e políticos que possam ser compartilhados entre suas instituições.

Respira-se em quase todos os setores da sociedade, inclusive na educação, um desejo de inovações. Seus agentes motivadores se fazem representar defendendo as novidades da era tecnológica da informação e comunicação, as novas condições para o conhecimento, o interesse em superar a fragmentação nos diversos campos do conhecimento, a busca de um saber interdisciplinar, as recentes revisões das carreiras e perfis profissionais até as demandas que o século XXI faz para a educação nos seus diferentes ângulos (MASETTO, 2011, p. 3).

Portanto, com base nestes pressupostos, questiona-se, como está a produção acadêmica, em periódicos indexados na área de Educação Física, sobre a Inovação Curricular no processo de formação profissional?

\section{PROCEDIMENTOS METODOLÓGICOS}

A pesquisa utiliza a característica qualitativa como método de abordagem do problema, pois busca os significados e interpretações das informações coletadas (MINAYO, 2009). Como método de procedimento utilizou-se da pesquisa bibliográfica, tendo como fontes as produções periódicas em revistas científicas da área de Educação Física.

Como critérios para a delimitação do estudo, os dados foram coletados dos periódicos científicos brasileiros com escopo na área de Educação Física, Esporte e Lazer, classificados entre os estratos A1 e B2 do Qualis Periódicos ${ }^{4}$ da CAPES $^{5}$ na plataforma SUCUPIRA ${ }^{6}$, na área de avaliação Educação Física e classificação nos anos de 2013-2016 ${ }^{7}$, na versão on-line.

Os periódicos são: Revista Brasileira de Medicina do Esporte, Revista Movimento, Motriz: Revista de Educação Física, Revista Brasileira de Cineantropometria e Desempenho Humano, Revista Brasileira de Educação Física e Esporte, Revista Brasileira de Ciências do Esporte, Licere, Pensar a Prática, Revista Brasileira de Biomecânica, Revista Brasileira de Ciência e Movimento e Revista Brasileira de Atividade Física e Saúde (Quadro 1). Nota-se que no quadro não aparece nenhum periódico A1, pois não existe periódico brasileiro, na área de Educação Física, classificado pela CAPES com este estrato. 
Quadro 1 - Periódicos brasileiros com QUALIS CAPES entre A1 e B2

\begin{tabular}{|c|c|c|c|}
\hline Nome do periódico & Endereço eletrônico & $\begin{array}{l}\text { ISSN - versão } \\
\text { on-line }\end{array}$ & Qualis \\
\hline $\begin{array}{l}\text { Revista Brasileira de } \\
\text { Medicina do Esporte }\end{array}$ & $\begin{array}{l}\text { https://rbme.org/ } \\
\text { http://www.scielo.br/cgi- } \\
\text { bin/wxis.exe/iah/ }\end{array}$ & $1806-9940$ & $\mathrm{~A} 2$ \\
\hline Revista Movimento & $\begin{array}{l}\text { https://seer.ufrgs.br/Movimento/inde } \\
\underline{\underline{x}}\end{array}$ & $1982-8918$ & A2 \\
\hline $\begin{array}{lll}\text { Motriz: } & \text { Revista de } \\
\text { Educação Física } & \end{array}$ & $\begin{array}{l}\text { http://www.scielo.br/scielo.php?scrip } \\
\mathrm{t}=\text { sci_serial\&pid=1980- } \\
\underline{6574 \& \operatorname{lng}=\text { en\&nrm=iso }}\end{array}$ & $1980-6574$ & B1 \\
\hline $\begin{array}{l}\text { Revista Brasileira de } \\
\text { Cineantropometria e } \\
\text { Desempenho Humano }\end{array}$ & $\begin{array}{l}\text { https://periodicos.ufsc.br/index.php/r } \\
\underline{\text { bcdh/index }} \\
\text { http://www.scielo.br/scielo.php?scrip } \\
\text { t=sci_serial\&pid=1980- } \\
\text { 0037\&lng=pt\&nrm=iso }\end{array}$ & 1980-0037 & B1 \\
\hline $\begin{array}{lrr}\text { Revista } & \text { Brasileira } & \text { de } \\
\text { Educação } & \text { Física } & \text { e } \\
\text { Esporte } & & \end{array}$ & $\begin{array}{l}\text { https://www.revistas.usp.br/rbefe } \\
\text { http://www.scielo.br/scielo.php?scrip } \\
\text { t=sci_serial\&pid=1807- } \\
\text { 5509\&lng=pt\&nrm=iso }\end{array}$ & $1981-4690$ & B1 \\
\hline $\begin{array}{l}\text { Revista Brasileira de } \\
\text { Ciências do Esporte }\end{array}$ & $\begin{array}{l}\text { http://revista.cbce.org.br/index.php/R } \\
\underline{\text { BCE/index }} \\
\text { http://www.scielo.br/scielo.php?scrip } \\
\text { t=sci_serial\&pid=0101- } \\
\text { 3289\&lng=pt\&nrm=iso }\end{array}$ & $2179-3255$ & B1 \\
\hline Licere & $\begin{array}{l}\text { https://periodicos.ufmg.br/index.php/ } \\
\text { licere/index }\end{array}$ & $1981-3171$ & B2 \\
\hline Pensar a Prática & https://www.revistas.ufg.br/fef/index & 1980-6183 & $\mathrm{B} 2$ \\
\hline $\begin{array}{l}\text { Revista Brasileira de } \\
\text { Biomecânica }\end{array}$ & $\begin{array}{l}\text { http://citrus.uspnet.usp.br/biomecan/ } \\
\text { ojs/index.php/rbb/index }\end{array}$ & $1518-8191$ & B2 \\
\hline $\begin{array}{l}\text { Revista Brasileira de } \\
\text { Ciência e Movimento }\end{array}$ & $\begin{array}{l}\text { https://portalrevistas.ucb.br/index.ph } \\
\text { p/RBCM }\end{array}$ & 0103-1716 & B2 \\
\hline $\begin{array}{l}\text { Revista Brasileira } \\
\text { Atividade } \\
\text { Saúde }\end{array}$ & http://www.rbafs.org.br/RBAFS & $2317-1634$ & B2 \\
\hline
\end{tabular}

Fonte: Plataforma Sucupira/CAPES. Disponível em:

https://sucupira.capes.gov.br/sucupira/public/consultas/coleta/veiculoPublicacaoQualis/listaConsultaGeralPeriod $\underline{\text { icos.jsf. }}$

Como critérios de inclusão, foram selecionados os artigos que apresentaram no título, palavras-chave ou resumo a palavra "Inovação" e mantinham relação direta da inovação com o currículo de graduação em Educação Física, ou seja, com a inovação curricular na formação profissional em Educação Física. 
No primeiro momento, a busca foi realizada nos últimos cinco anos de cada periódico, mas devido ao número reduzido de artigos localizados optou-se pela não delimitação temporal para o estudo.

Após a localização e organização dos artigos, conforme os critérios de delimitação e inclusão, foi realizada a leitura e análise dos artigos completos para identificação das principais conclusões dos estudos. Os dados foram organizados nas seguintes categorias de análise: nome do periódico, edição, autores, título, palavras-chave e, após a leitura, fatores que possibilitam a inovação curricular.

\section{RESULTADOS E DISCUSSÃO}

Foram localizados quatro (4) artigos com os critérios de delimitação e inclusão apresentados nos procedimentos metodológicos. Os periódicos foram: Revista Movimento, com três (3) artigos, e Revista Brasileira de Atividade Física e Saúde, com um (1) artigo (Quadro 2).

Quadro 2 - Periódicos brasileiros com Qualis CAPES entre A1 e B2 com artigos sobre inovação curricular na graduação em educação física

\begin{tabular}{|c|c|c|c|c|}
\hline Periódico & Edição & Autores & Título & Palavras-chave \\
\hline \multirow{3}{*}{$\begin{array}{c}\text { Revista } \\
\text { Movimento }\end{array}$} & $\begin{array}{l}\text { v.4, n. } 7 \\
1997\end{array}$ & $\begin{array}{c}\text { Vicente } \\
\text { Molina Neto }\end{array}$ & $\begin{array}{c}\text { A cultura do } \\
\text { professorado de } \\
\text { educação física das } \\
\text { escolas públicas de } \\
\text { Porto Alegre. }\end{array}$ & $\frac{\text { - Inovacão curricular. }}{\text { - Formação de professores. }}$ \\
\hline & $\begin{array}{l}\text { v. } 21, \mathrm{n} . \\
2, \\
\text { abr./jun. } \\
2015\end{array}$ & $\begin{array}{c}\text { Anísio } \\
\text { Calciolari } \\
\text { Junior, Jeane } \\
\text { Barcelos } \\
\text { Soriano }\end{array}$ & $\begin{array}{c}\text { A organização } \\
\text { político-científica nos } \\
\text { EUA nos anos de } \\
1960 \text { e seu impacto } \\
\text { para a dimensão } \\
\text { acadêmica da } \\
\text { educação física. }\end{array}$ & $\begin{array}{c}\text { - Política nacional de } \\
\text { ciência, tecnologia e } \\
\text { inovacão. } \\
\text { - Instituições acadêmicas: } \\
\text { organização \& } \\
\text { administração. } \\
\text { - História. } \\
\text { - Estados Unidos. }\end{array}$ \\
\hline & $\begin{array}{c}\text { v. } 25 \text {, } \\
\text { jan./ dez. } \\
2019\end{array}$ & $\begin{array}{l}\text { Bruno Barth } \\
\text { Pinto } \\
\text { Tucunduva, } \\
\text { Marco } \\
\text { Antonio } \\
\end{array}$ & $\begin{array}{c}\text { O circo e a inovacão } \\
\text { curricular na } \\
\text { formação de } \\
\text { professores de }\end{array}$ & $\begin{array}{l}\text { - Capacitação de } \\
\text { professores. } \\
\text { - Educação superior. } \\
\text { - Arte. } \\
\text { - Currículo. }\end{array}$ \\
\hline
\end{tabular}




\begin{tabular}{|c|c|c|c|c|}
\hline & & $\begin{array}{l}\text { Coelho } \\
\text { Bortoleto }\end{array}$ & $\begin{array}{c}\text { educação física no } \\
\text { Brasil. }\end{array}$ & \\
\hline $\begin{array}{c}\text { Revista } \\
\text { brasileira de } \\
\text { atividade } \\
\text { física \& } \\
\text { saúde } \\
\text { (RBAFS) }\end{array}$ & $\begin{array}{l}\text { v. } 21, \mathrm{n} . \\
3(2016)\end{array}$ & $\begin{array}{c}\text { Mathias } \\
\text { Roberto Loch } \\
\text { et al. }\end{array}$ & $\begin{array}{c}\text { Abordando Saúde } \\
\text { Coletiva no curso de } \\
\text { bacharelado em } \\
\text { Educação Física: } \\
\text { Relato de } \\
\text { experiência }{ }^{8} .\end{array}$ & $\begin{array}{l}\text { - Sistema Único de Saúde. } \\
\text { - Atenção Primária à Saúde. } \\
\text { - Prática profissional. } \\
\text { - Instituições acadêmicas. } \\
\text { - Recursos Humanos }\end{array}$ \\
\hline
\end{tabular}

Fonte: $\mathrm{O}$ autor, pesquisa documental.

O primeiro resultado a destacar é o reduzido número de artigos publicados sobre inovação curricular na graduação em Educação Física. Também, os artigos estão distanciados no tempo, por isso o estudo não fez uma delimitação temporal. Foram localizados apenas quatro (4) artigos, sendo, um (1) artigo de 1997, um (1) artigo de 2015, um (1) artigo de 2016 e um (1) artigo de 2019.

$\mathrm{Na}$ sequência, apresenta-se a interpretação sobre como a inovação curricular na graduação em Educação Física é tratada em cada artigo localizado.

O artigo intitulado "A cultura do professorado de educação física das escolas públicas de Porto Alegre", apesar de ser da década de 1990, contribui para a reflexão sobre inovação curricular na área por apresentar um aspecto ainda não superado na formação profissional em Educação Física. Apresenta a cultura docente como "um processo construtivo onde os professores de Educação Física, mediados pelo contexto, enlaçam e relacionam a experiência, a prática, o conhecimento, a formação e suas crenças” (MOLINA NETO, 1997, p. 39).

Enfatiza a atividade investigadora na formação de professores e a escola pública como local privilegiado para esta formação. Entende-se que a relação com a inovação curricular apresentada nessa pesquisa é a ideia de aproximar a universidade e a escola pública por meio de projetos e ações conjuntos.

[....] tratar velhas e constantes questões do professorado como formação, prática, conhecimento, etc, utilizando o conceito de cultura docente [...]. Além disso, abre perspectivas interessantes para seguir trabalhando, seja pesquisando e aprofundando cada um desses elementos constitutivos da cultura docente do professorado de Educação Física e desenvolvendo projetos de participação conjunta entre as escolas públicas e a universidade, seja no âmbito da formação, capacitando os alunos de Educação Física para a atividade investigadora e concebendo a escola pública como lugar privilegiado para a formação de professores de Educação Física (MOLINA NETO, 1997, p. 40). 
De certa forma, é interessante observar que essas ideias de aproximação da Universidade (Instituições de Ensino Superior) com as escolas estariam presentes, mais tarde, nas diretrizes curriculares para a formação de professores com o Parecer CNE/CP n 09/2001, Resolução CNE/CP n ${ }^{\circ}$ 01/2002 e Resolução CNE/CP nº 02/2002. Essa aproximação pode ser notada por meio da tese de doutorado de Antunes (2012) que, após análise das referidas Resoluções e Parecer, apresenta os pontos de destaque sobre a relação teoria e prática e concepção de prática no processo de preparação profissional em Educação Física, a saber: 1. Pesquisa e práticas investigativas; 2. Princípio metodológico da ação-reflexão-ação; 3. Relação com diferentes contextos; 4. Resolução de situações-problema; 5. Conhecimento advindo da experiência.

Portanto, o artigo apresenta um aspecto fundamental para o processo de inovação curricular na graduação, ou seja, o contexto em que o ensino ocorre e sua relação com a realidade.

O segundo artigo, “A organização político-científica nos EUA nos anos de 1960 e seu impacto para a dimensão acadêmica da educação física" (CALCIOLARI JUNIOR; SORIANO, 2015) apresenta uma discussão teórica sobre as influências de debates e transformações políticas no campo científico norte-americano, da década de 1960, para o status acadêmico da Educação Física, que veio a desencadear o chamado "Movimento Disciplinar" da área.

Foi a partir de tomadas de decisões políticas, traçando o futuro do campo científico, visando estabelecer um lugar social para a realização da pesquisa "livre e geradora de conhecimento básico" que a universidade se tornou, de forma legítima, o campo de produção de conhecimento [...] A EF, frente aos grupos de maior capital científico e às novas regras do campo da ciência, buscou criar suas estratégias de luta, alterando as regras em seu próprio campo social [...] Acreditamos que o movimento disciplinar sofreu pressões do campo científico e se reorganizou dentro dos moldes do que se esperava que fosse uma área de conhecimento científico (CALCIOLARI JUNIOR; SORIANO, 2015, p. 554).

É possível inferir desse estudo que transformações no campo político e científico determinam ações e movimentos que podem influenciar no processo de inovação curricular na formação profissional em Educação Física.

Dito de outra forma, é preciso analisar o contexto educacional, político e científico diante de suas relações e influências no processo de inovação curricular de determinada área de conhecimento. O campo político e o status social da área é determinante para alterar pontos- 
chave e elementos que constituem a área, ou seja, alteração no status e valorização da área perante a sociedade e os governantes e também, de forma inversa e complementar, é preciso inovar para que a sociedade e os governantes valorizem a área, proporcionando status social e acadêmico. É uma via de mão dupla.

O terceiro artigo analisado tem como título "Abordando Saúde Coletiva no curso de bacharelado em Educação Física: Relato de experiência" (LOCH et al., 2016) e descreve experiências e impressões sobre a disciplina "Educação Física e Saúde Pública". O estudo apresenta diferentes procedimentos de ensino como ações de inovação curricular.

No texto são apresentadas a descrição de algumas atividades que são trabalhadas nas aulas em que se busca alguma inovação a partir dos procedimentos de ensino adotados, entre os quais a discussão de pequenos textos, o relato e síntese das experiências dos alunos como usuários do Sistema Único de Saúde, um exercício que simula uma atividade de apoio matricial e aulas em que os alunos assistem alguns documentários (seguido pela discussão) (LOCH et al., 2016, p. 285).

Assim, o artigo apresenta como ações de inovação curricular experiências e procedimentos diferenciados de ensino. Mesmo não sendo procedimentos inéditos de maneira isolada, o artigo demonstra que, combinar e utilizar determinados procedimentos em diferentes espaços e com aproximação de estratégias diversas permitem ao graduando a compreensão do conteúdo de forma mais efetiva e, assim, proporcionam uma inovação curricular.

O último artigo analisado foi publicado com o título "O circo e a inovação curricular na formação de professores de educação física no Brasil” (TUCUNDUVA; BORTOLETO, 2019) e apresenta o circo como um conteúdo inovador nos currículos de graduação em Educação Física.

Consideramos que o circo é uma inovação pedagógica devido a suas contribuições à EF não se limitarem a ampliar o repertório cultural e de técnicas corporais. A pedagogia do circo na EF oferece uma lógica criativa para explorar o corpo e o movimento, que integra expressão artística à descoberta da capacidade e habilidade física. Ou seja, o circo busca descobrir formas "extraordinárias" de se mover e pôr o corpo, suas capacidades e habilidades como protagonistas da poética no palco (TUCUNDUVA; BORTOLETO, 2019, p. 02).

Os autores apresentam o conteúdo circo como uma inovação curricular e também com "poder suficiente para estimular novas reflexões e interações com os fundamentos mais elementares da EF” (TUCUNDUVA; BORTOLETO, 2019, p. 11). Dessa forma, a inovação 
curricular é apresentada com base em um conteúdo específico, com potencial para outras formas de inovação em um processo contínuo e criativo, por meio de ações no ensino, pesquisa e extensão, além de interação com outras áreas de conhecimento. Pensar em novos conteúdos significa olhar para as transformações e construções que ocorrem na sociedade e interagir com elas, ou seja, os conteúdos são pontos-chave e elementos constitutivos para a inovação curricular no processo de formação profissional.

Com base no que é apresentado nos quatro artigos analisados, destacam-se determinados fatores, como principais resultados da produção científica em artigos sobre inovação curricular, na graduação em Educação Física.

Quadro 3 - Fatores que possibilitam a inovação curricular na graduação em Educação Física nos artigos localizados nos periódicos brasileiros com QUALIS CAPES entre A1 e B2

\begin{tabular}{|c|c|}
\hline Título do artigo & $\begin{array}{c}\text { Fatores que possibilitam a inovação } \\
\text { curricular }\end{array}$ \\
\hline $\begin{array}{c}\text { A cultura do professorado de educação física das } \\
\text { escolas públicas de Porto Alegre }\end{array}$ & $\begin{array}{c}\text { - Cultura docente como um processo } \\
\text { construtivo mediado pelo contexto, } \\
\text { experiência, prática, conhecimento, formação e } \\
\text { crenças } \\
\text { - Projetos de participação conjunta entre as } \\
\text { escolas públicas e aniversidade }\end{array}$ \\
\hline $\begin{array}{c}\text { A organização político-científica nos EUA nos } \\
\text { anos de 1960 e seu impacto para a dimensão } \\
\text { acadêmica da educação física }\end{array}$ & $\begin{array}{c}\text { - Campo científico } \\
\text { - Campo social }\end{array}$ \\
\hline $\begin{array}{c}\text { O circo e a inovação curricular na formação de } \\
\text { professores de educação física no Brasil }\end{array}$ & $\begin{array}{c}\text { - Inovação pedagóncica sustentável } \\
\text { - Interação com a arte }\end{array}$ \\
$\begin{array}{c}\text { - Projetos de ensino, extensão e pesquisa } \\
\text { - Processo continuado de inovação curricular. } \\
\text { - Poder para estimular novas reflexões e } \\
\text { interações com os fundamentos mais } \\
\text { elementares da EF. }\end{array}$ \\
\hline $\begin{array}{c}\text { Abordando Saúde Coletiva no curso de } \\
\text { bacharelado em Educação Física: Relato de } \\
\text { experiência }\end{array}$ & $\begin{array}{c}\text { - Procedimentos de ensino (discussão de } \\
\text { pequenos textos, relato e síntese de } \\
\text { experiências, documentários seguidos de } \\
\text { discussão. }\end{array}$ \\
\hline
\end{tabular}

Fonte: $\mathrm{O}$ autor, pesquisa documental.

Consoante com os fatores apresentados no quadro 3 estabeleceram-se quatro categorias distintas nos artigos e que podem ser determinantes no processo de inovação curricular na graduação em Educação Física, a saber, 
- O contexto em que o ensino ocorre,

- O status científico e político da área,

- $\quad$ Os conteúdos a serem desenvolvidos e

- $\quad$ Os procedimentos de ensino.

Neste momento, é importante frisar, que apesar de existirem outros estudos acadêmicos sobre os assuntos das categorias estabelecidas, não surgiram, nos periódicos investigados, artigos que demonstrassem esta relação direta e interativa com o processo de inovação curricular no currículo de graduação em Educação Física, e que atendessem aos critérios de inclusão definidos para o estudo.

Dito isso, estas categorias mostram como a inovação curricular sobre a graduação em Educação Física está sendo pensada em pesquisas acadêmicas. A primeira categoria considera a contextualização do ensino em sintonia com a sociedade em que vivemos e seu novo paradigma da informação.

Com efeito, uma inovação curricular parte de sua Contextualização na Sociedade Contemporânea: procura identificar os novos cenários históricos, políticos, culturais; as ciências e a tecnologia nesse mundo; os valores e problemas que assolam as comunidades de adultos, de jovens, de crianças nas próximas décadas, no Brasil e no mundo. Esta contextualização permitirá definir o perfil do profissional competente e cidadão, explicitando as características que se elegem visando à formação de profissionais tais como hoje exigem a sociedade, as carreiras profissionais, o avanço das ciências e da tecnologia e sua responsabilidade social (MASETTO, 2011, p. 16).

O contexto é, portanto, a base para se pensar em um processo de inovação curricular e mantém relação direta com o status científico e político da área de Educação Física (segunda categoria) que vive uma constante busca e luta por sua valorização e reconhecimento social, tanto na universidade quanto na sociedade. O movimento disciplinar, analisado no artigo de Calciolari Junior e Soriano (2015) mostra como a área de Educação Física busca este reconhecimento acadêmico. No Brasil, com suas particularidades, isso também ocorre, inclusive com influência deste movimento, como já foi demonstrado em vários estudos (FARINATTI, 1992; SOUZA NETO, 2004; VERENGUER, 2003; TOJAL, 2004, REIS, 2003, TANI, 1996, ANTUNES, 2008), mas estes estudos não demonstram, de maneira explícita, interação ou ênfase para o processo de inovação curricular na graduação em Educação Física. 
Assim, outro ponto a ser considerado em um processo de inovação curricular na graduação em Educação Física é compreender este processo de valorização e reconhecimento social da área, ou seja, projetos e ações de inovação curricular devem buscar um elevado status acadêmico e político para o campo de conhecimento. Este processo determina a segunda categoria estabelecida no estudo. Conforme explica Masetto (2011, p. 17), "Vinculado a este processo de aprendizagem, temos encontrado também como característica de inovação curricular a ênfase em explicitar os princípios epistemológicos que respondem pela construção do conhecimento dos educandos".

As últimas duas categorias destacadas nos resultados, os conteúdos a serem desenvolvidos e os procedimentos de ensino, dizem respeito ao desenvolvimento de habilidades, competências, atitudes e valores, necessários para uma intervenção profissional eficiente.

O currículo entendido como um conjunto de aprendizagens que, por se considerarem social e profissionalmente necessárias num dado tempo e contexto, cabe à Instituição escolar garantir e organizar e é assumido como um projeto no qual participam ativamente professores e alunos em sua elaboração, execução e avaliação (MASETTO, 2011, p. 15-16).

Na busca da inovação curricular, percebe-se que é necessário superar metodologias e atitudes pedagógicas ultrapassadas por serem ineficientes nesta era da informação e sociedade em rede. Como afirma Masetto (2011), novas propostas metodológicas, nova postura dos alunos, nova postura do professor, novos espaços e tempos da universidade são caminhos para projetos inovadores no ensino superior.

Nesta linha de raciocínio, com especificidade para a formação de educadores, Feldmann et al. (2016, p. 1132) argumentam que, os estudos que têm desenvolvido sobre a articulação entre formação de educadores e currículo “[...] remetem para a problematização e a investigação sobre o entrecruzamento de práticas docentes em diversas dimensões: epistemológica, política, econômica, cultural, ideológica, técnica, ética, estética e histórica".

Dessa forma, apesar das categorias identificadas nos artigos analisados estarem em sintonia com o conceito apresentado de inovação curricular no ensino superior e representarem importantes exemplos de ações a serem replicadas e ampliadas, não é possível afirmar que existe um movimento de inovação curricular na graduação em Educação Física. Pois, o número 
de artigos é reduzido, as publicações estão muito distanciadas no tempo e não existe uma linha de debate ou referencial teórico dominante sobre o tema, o que é reforçado pelos motivos anteriores.

Conforme aventado anteriormente, sobre os três caminhos que o processo de inovação curricular na formação profissional em Educação Física poderia seguir, os resultados deixam claro que as iniciativas são isoladas, apesar de valiosas. Porém, o processo é coletivo.

Esse fato leva ao distanciamento da área das discussões mais consistentes e práticas mais eficientes que possam proporcionar uma transformação dos modelos ultrapassados que ainda persistem no ensino de graduação em Educação Física. Deste modo, como advoga Tani (2013, p. 555-556, tradução nossa),

[...] programas de preparação profissional precisam ser formativos em vez de informativo e preparar profissionais capazes de usar pensamento e métodos científicos para resolver problemas práticos de intervenção [...] É importante reconhecer que os cursos de preparação profissional estão essencialmente preocupados com um conjunto de conhecimentos historicamente construídos na área. Essa mudança de mentalidade e expectativa resultará em uma atitude muito mais positiva em relação à busca e aquisição de conhecimento?.

Assim sendo, atualmente existem muitas estratégias e ações que podem ser utilizadas em um projeto de inovação curricular. A Educação Física precisa apropriar-se delas para uma proposta mais ampla de inovação que seja eficaz e eficiente na formação dos futuros profissionais/professores.

\subsection{Estudos sobre inovação curricular na graduação em outras áreas: possibilidades para a Educação Física}

Na sequência, serão apresentados alguns estudos com diferentes estratégias e ações, a título de reflexão e apontamento de outras possibilidades para a inovação curricular na graduação. Contudo, não fizeram parte dos artigos analisados, por não indicarem relação explícita com a Educação Física, de acordo com os critérios de inclusão, ou seja, são apresentados como exemplos a seguir.

Tecnologias da Informação e Comunicação (TIC), por exemplo, são ferramentas de transformação e melhoria da docência universitária. Os resultados do estudo de Tomás et al. 
(2005-2006) sobre o uso das TIC como ferramenta de transformação da docência universitária mostram evidente percepção dos alunos sobre a melhora da docência.

Outro aspecto a ser observado no processo de inovação curricular são os modelos de formação docente. Keller-Franco (2018), a partir de uma análise de experiência curricular inovadora em uma Universidade, destaca alguns fatores importantes para a revisão destes, como

unidade entre teoria e prática na construção do conhecimento; integração entre universidade e escolas da Educação Básica em um sentido de fortalecimento mútuo; articulação dos saberes em uma perspectiva de ruptura epistemológica que leva em consideração as experiências de vida de cada aluno e a constituição de novos espaços de aprendizagem para além dos muros da universidade (KELLER-FRANCO, 2018, 694).

Pensar em diferentes metodologias de aprendizagem também é um caminho interessante para a inovação curricular. A Pesquisa e Inovação Responsáveis (Responsible Research and Innovation - RRI) e Aprendizagem Baseada em Projetos (Project-Based Learning - PBL) são duas estratégias eficientes para projetos de inovação curricular, conforme demonstrado em estudos de Oliveira e Mattar Neto (2018), Pinto e Ribeiro (2018), Souza et al. (2018). Criar modelos de ensino, com base em diferentes metodologias como a RRI, para transformar a prática pedagógica no ensino superior também é uma iniciativa eficiente, como mostra o estudo de Lima e Struchier (2018) sobre o desenvolvimento do modelo e-CRIA para a aprendizagem de Ciências, que estimula o pensamento crítico, debates em sala de aula e a participação ativa dos alunos.

Outra possibilidade é a integração, no ensino superior, de Tecnologias Digitais (TD) com uma estratégia denominada de coreografia didática, apresentado por Padilha e Beraza (2016) em um estudo com alunos de doutorado de uma universidade espanhola e outra brasileira, participantes de um curso de extensão semipresencial. Segundo os autores, o estudo promoveu aprendizagem profunda e significativa.

Inúmeros exemplos poderiam ser apresentados, mas o objetivo é demonstrar que a Educação Física deve estar atenta para estas e outras possibilidades e, conforme as necessidades surjam, estabelecer estratégias próprias à sua realidade e especificidade. 


\section{CONSIDERAÇÕES FINAIS}

As categorias identificadas com a análise da produção de artigos (o contexto em que o ensino ocorre, o status científico e político da área, os conteúdos a serem desenvolvidos e os procedimentos de ensino), mostram que a inovação curricular é uma preocupação e necessária para a formação profissional de qualidade em Educação Física.

Para que a Educação Física continue exercendo seu papel fundamental na nossa sociedade é imprescindível uma aproximação com este tema, por meio de uma crescente produção de pesquisas. Contudo, neste momento, pelo reduzido número de pesquisas o que se observa é um distanciamento geral da área sobre o tema da inovação curricular na graduação, apesar dos estudos identificados mostrarem-se como importantes referências.

Analisar a formação profissional em Educação Física no Brasil pelo viés da inovação curricular deve compreender os elementos que constituíram a elaboração dos currículos de graduação, deve buscar compreender como as Instituições de Ensino Superior pensam as mudanças necessárias para que a inovação ocorra.

Em uma sociedade baseada no paradigma da informação (era da informação), em constante transformação, deve-se pensar na inovação curricular, ou seja, olhar para a realidade, para o contexto social, para as dificuldades e necessidades que o profissional irá encontrar no seu contexto de atuação profissional atual e futuro.

Esses argumentos indicam a necessidade do aprimoramento constante no processo de formação profissional em Educação Física no Brasil. Também, é fundamental olhar as experiências e conhecimentos de Instituições de Ensino Superior (IES) que possuem destaque na área.

São necessárias pesquisas que identifiquem ações e propostas de inovação curricular, como análises de projetos pedagógicos dos cursos de graduação em Educação Física, pesquisas realizadas nos cursos de mestrado e doutorado, e posicionamentos dos profissionais/professores responsáveis pelas reformas curriculares. Também, um olhar para experiências bem-sucedidas é de extrema importância para auxiliar na implantação e desenvolvimento desta nova realidade na educação brasileira, auxiliando no aprimoramento do ensino, aprendizagem e formação de professores/profissionais. 


\section{REFERÊNCIAS}

ANTUNES, Alfredo Cesar. Identidade acadêmica da educação física: da necessidade de um corpo de conhecimento teórico e fuga do rótulo de profissão prática para uma área que exerce a prática reflexiva. Anuário da Produção Acadêmica Docente, Valinhos, v.7, nº 2, p. 215229, 2008. Disponível em: https://repositorio.pgsskroton.com//handle/123456789/1538.

Acesso em: 20 fev. 2019.

ANTUNES, Alfredo Cesar. Influência da Resolução 03/87 para o atual processo de preparação profissional em Educação Física. Lecturas: educación física y deportes. Revista Digital, Buenos Aires, v. 14, nº 138, p. 1, nov. 2009. Disponível em:

https://www.efdeportes.com/efd138/resolucao-03-87-em-educacao-fisica.htm. Acesso em: 10 fev. 2019.

ANTUNES, Alfredo Cesar. A dimensão prática na preparação profissional em Educação Física: concepção e organização acadêmica. 2012. Tese (Doutorado em Ciência do Desporto) - Universidade Estadual de Campinas, Campinas, 2012. Disponível em:

http://repositorio.unicamp.br/jspui/handle/REPOSIP/275035. Acesso em: 10 fev. 2019.

BENITES, Larissa Cerignoni; SOUZA NETO, Samuel de; HUNGER, Dagmar. O processo de constituição histórica das diretrizes curriculares na formação de professores de Educação Física. Educação e Pesquisa, São Paulo, v. 34, nº 2, p. 343-360, maio/ago. 2008. Disponível em: http://hdl.handle.net/11449/8348. Acesso em: 12 dez. 2019.

BRACHT, Valter. Educação Física \& ciência: cenas de um casamento (in)feliz. Revista Brasileira de Ciências do Esporte, v. 22, nº 1, p.53-63, mai. 2000. Disponível em: http://revista.cbce.org.br/index.php/RBCE/article/view/753. Acesso em: 10 dez. 2019.

BRASIL. Resolução CNE/CP n 01, de 18 de fevereiro de 2002, fixa Diretrizes Curriculares Nacionais para a Formação de Professores em Educação Básica. Brasília, 2002a.

BRASIL. Resolução CNE/CP n⿳0 02, de 19 de fevereiro de 2002, fixa Diretrizes Curriculares Nacionais para a Formação de Professores em Educação Básica. Brasília, 2002b.

BRASIL. Resolução CNE/CES n. ${ }^{0}$ 07, de 31 de março de 2004, fixa Diretrizes Curriculares Nacionais para os cursos de graduação em Educação Física, em nível superior de graduação plena, Brasília, 2004.

BRASIL. Governos divulgam plano de legado dos Jogos Rio 2016. Publicado: 16/04/2014. Disponível em: http://www.brasil.gov.br/governo/2014/04/governos-divulgam-plano-depoliticas-publicas-de-legado. Acesso em: 12 jan. 2018.

BRASIL. Ministério do Esporte. Legados de megaeventos esportivos. CONFEF/Ministério do Esporte, 2008. 
BRASIL. Ministério da Educação. e-MEC. Instituições de Educação Superior e Cursos Cadastrados. Disponível em: http://emec.mec.gov.br/. Acesso em: 11 jan. 2018.

CALCIOLARI JUNIOR, Anísio; SORIANO, Jeane Barcelos. Movimento. A organização político-científica nos EUA nos anos de 1960 e seu impacto para a dimensão acadêmica da educação física. v. 21, $\mathrm{n}^{\circ}$ 2, p. 545-558, abr.jun. 2015. Disponível em:

https://seer.ufrgs.br/Movimento/article/view/48111. Acesso em: 08 jan. 2020.

CASTELLS, Manuel. A Sociedade em Rede. São Paulo: Paz e Terra, 2012.

FARINATTI, Paulo de Tarso Veras. Pesquisa em Educação Física no Brasil: por um compromisso com a evolução. In: FARIA JR., Alfredo Gomes; FARINATTI, Paulo de Tarso V. (Orgs.). Pesquisa e produção do conhecimento em educação física: livro do ano 1991/SBDF. Rio de Janeiro: Ao Livro Técnico, 1992. p. 34-68.

FELDMANN, Marina et al. Formação inicial de educadores: currículo, trabalho pedagógico e inovação. Revista e-Curriculum, São Paulo, v. 14, nº 03, p. 1130 - 1150, jul./set.2016. Disponível em: https://revistas.pucsp.br/curriculum/article/view/29312/20686. Acesso em: 20 jan. 2020.

KELLER-FRANCO, Elize. Modelos de formação docente em projetos curriculares inovadores: reflexões a partir de uma experiência formativa. Revista e-Curriculum, São Paulo, v. 16, nº 3, p. 694-720, jul./set. 2018. Disponível em:

https://revistas.pucsp.br/curriculum/article/view/34018. Acesso em: 07 jan. 2020.

LÉVY, Pierre. Cibercultura. São Paulo: Editora 34, 1999.

LIMA, Marcelo Bernardo de; STRUCHIER, Miriam. Pressupostos teóricos e propostas para discutir questões sociocientíficas: construção do modelo E-CRIA e sua aplicação no ensino superior. Revista e-Curriculum, São Paulo, v. 16, nº 2, p. 393-419, abr./jun. 2018.

Disponível em: https://revistas.pucsp.br/curriculum/article/view/36870. Acesso em: 08 jan. 2020.

LOCH, Mathias Roberto et al. Abordando Saúde Coletiva no curso de bacharelado em Educação Física: Relato de experiência. Revista Brasileira de Atividade Física e Saúde (RBAFS). v. 21, no 3, p. 285-290, 2016. Disponível em:

http://rbafs.org.br/RBAFS/article/view/7479. Acesso em: 12 jan. 2020.

MARINHO, Alcyane; NASCIMENTO, Juarez Vieira do; OLIVEIRA, Amauri Aparecido Bássoli (Orgs.). Legados do esporte brasileiro. Florianópolis: Ed. da UDESC, 2014.

MASETTO, Marcos. Inovação na Educação superior. Interface- Comunicação, Saúde, Educação, Botucatu, v. 8, no 14, p. 197-202, set. 2003-fev.2004. Disponível em: https://doi.org/10.1590/S1414-32832004000100018. Acesso em: 01 jul. 2018. 
Programa de Pós-Graduação em Educação: Currículo

MASETTO, Marcos Tarciso. Inovação Curricular no Ensino Superior. Revista e-curriculum, São Paulo, v. 7, no 2, p. 1-20, agosto 2011. Disponível em:

http://revistas.pucsp.br/index.php/curriculum. Acesso em: 08 jan. 2018.

MINAYO, Maria Cecília de Souza (Org.). Pesquisa social: teoria, método e criatividade. 28. ed. Petrópolis, RJ: Vozes, 2009.

MOLINA NETO, Vicente. A cultura do professorado de educação física das escolas públicas de Porto Alegre. Movimento, Porto Alegre, v. 4, no 7. 1997. Disponível em:

https://seer.ufrgs.br/Movimento/article/view/2365. Acesso em: 10 jan. 2020.

MOTTA, Vânia Cardoso da; FRIGOTTO, Gaudêncio. Por que a urgência da reforma do ensino médio? Medida provisória no 746/2016 (lei no 13415/2017). Educação e Sociedade: revista de ciência da educação, Campinas, v. 38, nº 139, p. 355-372, abr./jun. 2017. Disponível em: https://www.scielo.br/scielo.php?pid=S010173302017000200355\&script=sci_abstract\&tlng=pt. Acesso em: 02 ago. 2018.

OLIVEIRA, Neide Aparecida Arruda de; MATTAR NETO, João Augusto. Folhetim Lorenianas: aprendizagem baseada em projetos, pesquisa e inovação responsáveis na educação. Revista e-Curriculum, São Paulo, v. 16, nº 2, p. 341-363, abr./jun. 2018. Disponível em: https://revistas.pucsp.br/index.php/curriculum/article/view/36767. Acesso em: 11 jan. 2020.

PADILHA, Maria Auxiliadora Soares; BERAZA, Miguel Angel Zabalza. Um cenário de integração de tecnologias digitais na educação superior: em busca de uma coreografia didática inovadora. Revista e-Curriculum, São Paulo, v. 14, nº 3, p. 837-863, jul./set. 2016.

Disponível em: https://revistas.pucsp.br/curriculum/article/view/28698. Acesso em: 12 jan. 2020.

PINTO, Sonia Maria Conceição; RIBEIRO, Silvar Ferreira. Pesquisa e inovação responsáveis na formação científica dos estudantes da educação superior. Revista e-Curriculum, São Paulo, v. 16, n 2, p. 420-444, abr./jun.2018. Disponível em: https://revistas.pucsp.br/curriculum/article/view/36875. Acesso em: 14 jan. 2020.

REIS, Marize Cisneiros da Costa. A legitimidade acadêmico-científica da Educação Física: uma investigação. 2003. Tese (Doutorado em Pedagogia do Movimento) - Universidade Estadual de Campinas, Campinas, 2003.

SOUZA, Karine Pinheiro de et al. Ciência na praça: um diálogo com a responsabilidade e inovação na pesquisa. Revista e-Curriculum, São Paulo, v. 16, nº 2, p. 315-340, abr./jun. 2018. Disponível em: https://revistas.pucsp.br/index.php/curriculum/article/view/36869. Acesso em: 15 jan. 2020.

SOUZA NETO, Samuel et al. A formação do profissional de educação física no Brasil: uma história sob a perspectiva da legislação federal no século XX. Revista Brasileira de Ciências 
TANI, Go. Cinesiologia, Educação Física e Esporte: Ordem emanente do caos na estrutura acadêmica. Motus Corporis: revista de divulgação científica do mestrado e doutorado em educação física. v. 3, nº 2, p. 9-49, 1996.

TANI, Go. Professional preparation in physical education: Changing labor market and competence. Motriz, Rio Claro, v.19 n.3, p.552-557, jul/sep. 2013. Disponível em: http://www.scielo.br/scielo.php?script=sci_arttext\&pid=S1980-65742013000300004. Acesso em: 10 jan. 2018.

TOJAL, João Batista Andreotti Gomes. Da educação física a motricidade humana: a preparação do profissional. Lisboa: Instituo Piaget, 2004.

TOMÁS, Marina et al. Extensão da inovação docente sobre o uso das TIC na Faculdade de Ciências da Educação da Universidade Autonoma de Barcelona. Revista e-Curriculum, São Paulo, v. 1, $\mathrm{n}^{\circ}$ 1, p. 1-30, dez./jul. 2005-2006. Disponível em: https://revistas.pucsp.br/curriculum/article/view/3096. Acesso em: 08 jan. 2020.

TUCUNDUVA, Bruno Barth Pinto; BORTOLETO, Marco Antonio Coelho. O circo e a inovação curricular na formação de professores de educação física no Brasil. Revista

Movimento. v. 25, p.1-13, jan./ dez. 2019. Disponível em:

https://seer.ufrgs.br/Movimento/article/view/88131. Acesso em: 20 jan. 2020.

VERENGUER, Rita de Cassia Garcia. Mercado de trabalho em educação física:

significado da intervenção profissional à luz das relações de trabalho e da construção da carreira. 2003. Tese (Doutorado em Educação Física) -Universidade Estadual de Campinas, Campinas, 2003. Disponível em:

http://repositorio.unicamp.br/jspui/handle/REPOSIP/275452. Acesso em: 18 jan. 2019.

\section{NOTAS:}

\footnotetext{
${ }^{1}$ Existem vertentes favoráveis e contrárias à regulamentação da profissão de Educação Física, porém não é escopo deste trabalho analisar este fato.

${ }^{2}$ Conferir: http://portal.mec.gov.br/component/content/article?id=40361.

${ }^{3}$ Conferir: http://basenacionalcomum.mec.gov.br/.

${ }^{4}$ É um sistema usado para classificar a produção científica dos programas de pós-graduação no que se refere aos artigos publicados em periódicos científicos. Disponível em: https://sucupira.capes.gov.br/sucupira/public/index.xhtml\#.

${ }^{5}$ Coordenação de Aperfeiçoamento de Pessoal de Nível Superior (CAPES), fundação do Ministério da Educação (MEC).

${ }^{6}$ É o módulo que permite a classificação e consulta ao Qualis das áreas, bem como a divulgação dos critérios utilizados para classificação de periódicos. Disponível em: https://sucupira.capes.gov.br/sucupira/public/index.xhtml\#.
} 
Programa de Pós-Graduação em Educação: Currículo

7 Última classificação disponível. Nas Classificações de 2010-2012 e 2013-2016, os veículos receberam classificações em estratos indicativos de qualidade A1, mais elevado; A2; B1; B2; B3; B4; B5; C - peso zero. Na Classificação de 2017-2020, os veículos poderão ser classificados nos seguintes estratos: A1, mais elevado; A2; A3; $\mathrm{A} 4 ; \quad \mathrm{B} 1 ; \quad \mathrm{B} 2 ; \quad \mathrm{B} 3 ; \quad \mathrm{B} 4 ; \quad \mathrm{C} \quad-\quad$ peso zero. Disponível em: https://sucupira.capes.gov.br/sucupira/public/index.xhtml\#.

${ }^{8}$ Este artigo apresenta a palavra "inovação" no resumo.

9 “[...] professional preparation programs need to be formative instead of informative and prepare professionals capable of using scientific thinking and method to solve practical problems of intervention [...] It is important to recognize that the professional preparation courses are essentially concerned with a body of knowledge historically constructed in the area. This mentality and expectation change will result in an attitude much more positive in relation to the search and acquisition of knowledge" (TANI, 2013, p. 555-556).

Recebido em: 14/05/2020

Aprovado em: 26/08/2020 